\title{
ACUTE DIVERTICULITIS IN COVID-19 PATIENTS: PARALLEL MANAGEMENT IN THREE CASES. ARE THE GUIDELINES ADAPTING?
}

\section{DIVERTICULITE AGUDA EM PACIENTES COM COVID-19: MANEJO PARALELO EM TRÊS CASOS. AS DIRETRIZES ESTÃO SE ADAPTANDO?}

\author{
Claudio Guerci ${ }^{1}$; Gloria Goi ${ }^{1}$; Anna Maffioli1 ${ }^{1}$; Andrea Bondurri ${ }^{1}$; Piergiorgio Danelli ${ }^{1}$.
}

\begin{abstract}
Introduction: One concern in COVID-19 era is to treat surgical cases. According to the literature, a positive Sars-CoV-2 swab should delay surgery. The decision-making process is more challenging in cases of emergency. This report aims to present the management of acute diverticulitis in COVID patients. Case report: Three cases of perforated diverticulitis in COVID patients occurred in our institution. Two cases, whose one was symptomatic for COVID, underwent a Hartmann procedure. In the third case, a percutaneous drainage was performed, because of age and comorbidities. No complications occurred. A perianal swab and a drainage fluid swab were collected. The rRT-PCR analysis was negative for Sars-CoV-2. The decision-making process in cases of emergency surgery during a Sars$\mathrm{CoV}-2$ infection is challenging. It is demonstrated that a positive Sars-CoV-2 swab should delay surgery, but we need evidence on the management of COVID-19 surgical patients during emergencies. We tried conservative solutions and avoided excessive exposition of the personnel. When pulmonary and general conditions allowed a surgical approach, we performed it. We did not find any viral presence in our patients' body fluids and gastrointestinal samples. On the other hand, some authors reported the presence of the virus in feces specimens and anal swab tests. These contradictory findings are yet to be confirmed. Conclusion: The management of surgical emergencies in COVID-19 patients is challenging. The present work aims to give a contribution to the management of such surgical emergencies, as well as to warn colorectal surgeons about possible challenges.
\end{abstract}

Keywords: Diverticulitis. Colorectal Surgery. Coronavirus Infections.

\section{RESUMO}

Introdução: Uma preocupação na era COVID-19 é tratar os casos cirúrgicos. A literatura prevê que com um teste positivo a cirurgia seja postergada. O processo de tomada de decisão é mais desafiador em emergência. O presente relato pretende apresentar o manejo de diverticulite em pacientes com COVID. Relato do caso: Três casos de diverticulite perfurada em pacientes com COVID ocorreram em nossa instituição. Dois casos, sendo um deles sintomático para COVID, foram submetidos a procedimento de Hartmann. No terceiro caso, foi realizada drenagem percutânea, devido à idade e às comorbidades. Não ocorreram complicações. Um swab perianal e de fluido de drenagem foram coletados. A análise foi negativa para Sars-CoV-2. O processo de tomada de decisão em casos de cirurgia de emergência durante uma infecção por Sars-CoV-2 é desafiador. É demonstrado que com um teste positivo, a cirurgia seja postergada, mas precisamos de evidências sobre o manejo de pacientes cirúrgicos COVID-19 durante as emergências. Tentamos soluções conservadoras e evitamos a exposição excessiva do pessoal. Quando as condições pulmonares e gerais permitiam uma abordagem cirúrgica, nós a realizávamos. Não encontramos qualquer presença viral no teste de estoma, nem anal. Por outro lado, alguns autores relataram a presença do virus em fezes e testes de swab anal. Esses achados contraditórios ainda precisam ser confirmados. Conclusão: O gerenciamento de emergências cirúrgicas em pacientes com COVID-19 é desafiador. O presente trabalho visa contribuir para o manejo dessas emergências cirúrgicas, bem como alertar os cirurgiões colorretais sobre possiveis desafios.

Palavras-chave: Diverticulite. Cirurgia Colorretal. Infecções por Coronavirus. 
Guerci et al.

Acute diverticulitis in COVID-19 patients: parallel management in three cases. Are the guidelines adapting?

Relato de caso

\section{INTRODUCTION}

The impact of the COVID-19 pandemic on surgical emergencies requires to be understood and governed, especially for patients affected by an urgent surgical problem and a concomitant COVID-19 disease. This is a challenging topic because indications for emergency surgery under the pandemic of COVID-19 should be the same as before in conventional patients. Nevertheless, the main concern is to balance the timely treatment of these urgent cases, considering perioperative morbidity and mortality due to the novel coronavirus ${ }^{1}$.

The first data in the literature show that perioperative Sars-CoV-2 infection is associated with high mortality and suggest the promotion of non-operative treatment to delay or avoid surgery ${ }^{2,3}$. More specifically, another study provides that a positive SarsCoV-2 swab should delay surgery for at least 4 weeks, to reduce perioperative mortality ${ }^{4}$. The decision-making process is even more challenging in cases of emergency, where surgery needs to be performed and COVID-19 infection cannot be ruled out. We know that, when compared to nonCOVID patients, subjects with suspected or confirmed COVID-19 require more frequent postoperative follow-up checks, and comorbidities must be actively managed ${ }^{1}$.

As members of a Colorectal Unit, we wondered whether evidence on the management of COVID patients needing urgent colorectal surgery was currently listed in the literature. As with other Authors 5 , we attempted to adhere to the most recent general guidelines for the treatment of acute diverticulitis ${ }^{6}$ as closely as possible.

We then attempted to combine the current European guidelines, which were written just before the pandemic, with indications from the "COVID age" literature.

The present report aims to present the parallel management of three cases of acute diverticulitis in COVID-19 patients, as well as to arouse a debate on expert opinions. In other words, we think that recommendations and practical guidance are very important for the evaluation and management of acute diverticulitis and other colorectal emergencies.

\section{CASE REPORT}

\section{CASE 1}

A 53-year-old woman self-presented to the emergency room of Luigi Sacco Hospital, Milan, for dyspnea, fever $\left(39.4^{\circ} \mathrm{C}\right)$, and a documented direct contact with a COVID-19 patient. The woman had a noncontributory past medical history, or smoking history. She reported no allergies nor drugs taken at home regularly.

At admission, her blood test showed elevated white blood cell count (10'300 x $\left.10^{\wedge} 9 / \mathrm{L}\right)$ and CRP $(147 \mathrm{mg} / \mathrm{dL})$, together with an increased D-dimer $(2083 \mathrm{mcg} / \mathrm{L})$.

Her swab test for Sars-CoV-2 had a positive result. A chest X-Ray was performed, which showed bilateral areas of interstitium-alveolar consolidation. Therefore, she was admitted to the infectious disease department with a diagnosis of respiratory failure.

The patient was administered highflow oxygen therapy through C-PAP, antithrombotic prophylaxis, intravenous fluids, and antipyretic therapy. During the hospitalization, experimental treatments were administered, such as lopinavir/ritonavir, hydroxychloroquine, and even tocilizumab, with a slow progressive amelioration in respiratory symptoms and clinical presentation.

On the fifteenth post-admission day, an episode of diarrhea, correlated with abdominal pain, and an elevation of the white blood cells count was observed $(21 ' 700 \mathrm{x}$ $\left.10^{\wedge} 9 / \mathrm{L}\right)$, with stable CRP values (16.1 $\mathrm{mg} / \mathrm{dL}$ ). The chest X-Ray displayed a partial resolution of the bilateral pneumonia signs (Figure 1). The physical examination revealed mild abdominal distension and tenderness in the left bottom quadrant, without signs of peritonitis. An abdominal CT scan with contrast was then performed, which attested a pneumoperitoneum with free abdominal fluid; the images also showed an extended diverticular disease (previously unknown), with a perforation of a diverticulum in the distal sigmoid colon. These findings were linked to a pelvic abscess in close proximity to some ileal loops that appeared acutely inflamed. 


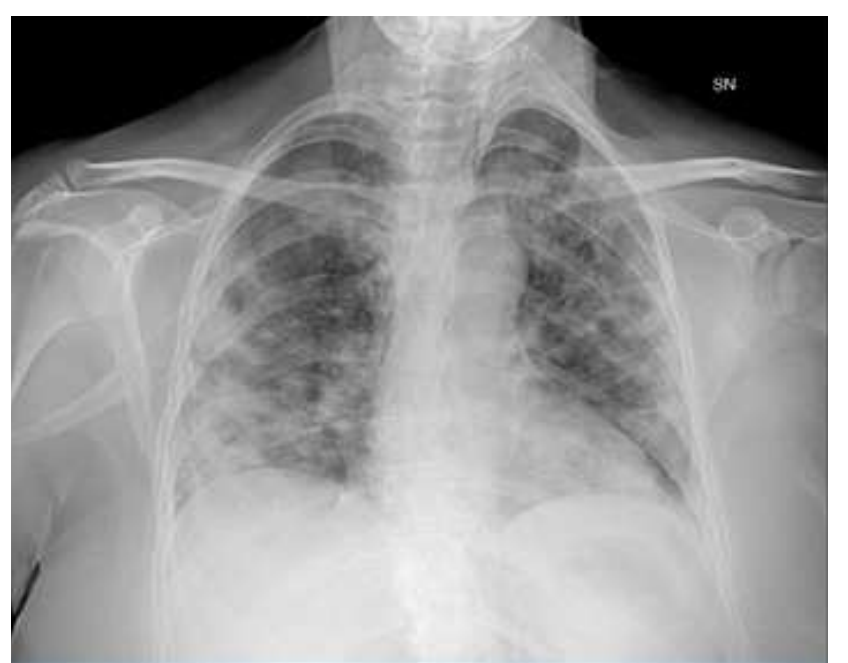

Figure 1. Preoperative chest X-Ray (Case 1) showing bilateral areas of interstitium-alveolar consolidation

The nasopharyngeal swab-test was still mild positive for Sars-CoV-2 infection.

Even if the lung disfunction was still substantial, the risk evaluation made us take a choice, after a consultation with our anesthesiologists and pneumologists. Therefore, an urgent explorative laparotomy was then performed, a resection of the affected sigmoid colon was carried out, and a temporary terminal colostomy was created (Hartmann's procedure). Moreover, antibiotic therapy with meropenem and vancomycin was administered. After the intervention, the patient spent a few days in the Intensive Care Unit, for postoperative resuscitation. Then, we observed a slow, gradual improvement in the patient's general and respiratory conditions during the subsequent postoperative days. The patient underwent a long course of respiratory and physical rehabilitation. She was adequately trained for the maintenance of her colostomy and was discharged on the 29th postoperative day, with a series of three negative nasopharyngeal swab tests.

\section{CASE 2}

A 44-year-old woman was referred to our emergency room for acute abdominal pain, fever, and diarrhea. Five days before, she had had a job-screening swab test for Sars-CoV-2 that had resulted positive. She had no symptoms of Sars-CoV-2 infection. The patient had a history of benign mammary lesion resection. She had no smoking history, nor allergies. She did not take any drugs regularly.
In the emergency room, her blood tests showed an elevation in inflammation indexes (white blood cells 14'150 x 10^9/L and CRP $378 \mathrm{mg} / \mathrm{dL}$ ). The chest X-Ray did not report any signs of inflammation nor infection.

An abdominal $\mathrm{CT}$ with contrast was performed, which showed a pelvic abscess (about $5 \mathrm{~cm}$ in diameter), in continuity with a diverticular formation in the mediumterminal tract of the sigmoid colon. Because of the size of the abscess, a conservative treatment was initially tried. The patient remained fast. She was administered antibiotic therapy with piperacillin/tazobactam and levofloxacin, hydroxychloroquine, thrombotic prophylaxis, and transferred to another sub-intensive institution, for therapy and clinical monitoring.

After fourteen days from the discharge, the patient was readmitted to our emergency room with fever and abdominal pain. Physical examination revealed tenderness in the inferior abdominal quadrants, with peritonism signs. Blood tests showed elevated white blood cell count (19'890 cells $\left.\mathrm{x} 10^{\wedge} 9 / \mathrm{L}\right)$ and CRP $(227 \mathrm{mg} / \mathrm{dL})$. The chest X-ray displayed no pathological features (Figure 2). Another abdominal CT with contrast was performed: a volume increase of the pelvic abscess was documented, reaching $11 \times 6 \times 5,5 \mathrm{~cm}$, with pneumoperitoneum and an air-fluid level in the middle of the collection; the sigmoid colon walls appeared thickened and edematous, as in an acute inflammatory condition.

The last positive nasopharyngeal swab-test for Sars-CoV-2 infection had been made eight days before. A negative swab test was found two days before the readmission. In the absence of pulmonary disfunction and with a recent negative swab test, the scale was tipped in favor of the abdominal status.

For these reasons, an urgent explorative laparotomy was conducted, and, after drainage and accurate washing of the pelvic cavity, a Hartmann's procedure was carried out, with the creation of a temporary terminal colostomy on the left side of the abdominal wall. Antibiotic therapy with meropenem was then administered. Subsequently, a progressive recovery was observed, with an improvement in her general condition, successful stoma training, and 
physical rehabilitation. The patient was discharged home on the 13th postoperative day, with two documented negative nasopharyngeal swab tests.

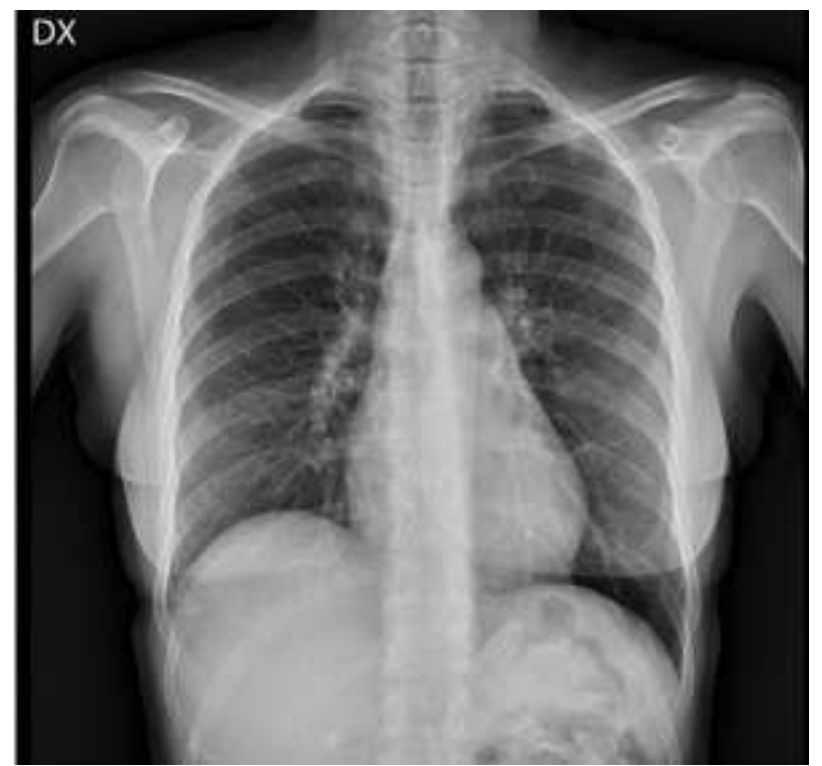

Figure 2. Preoperative chest X-Ray (Case 2). No signs of inflammation/infection were reported.

\section{CASE 3}

A 76-year-old man was conducted by his daughter to the emergency room of Luigi Sacco Hospital. He complained of fever for a few days, and he was under quarantine, waiting for the result of his swab test. The patient had a history of COPD, epilepsy, HCV hepatitis, and a recent diagnosis of Alzheimer's disease. He regularly took valproic acid and vitamin $B$ complex at home. No allergies were reported. His blood tests revealed a normal white blood cell count and an increase in CRP levels (97 $\mathrm{mg} / \mathrm{dL}$ ) at the time of admission. A chest ultrasound displayed a bilateral B-2 pattern with a left basal opacity and mild pleural effusion; a chest X-ray showed an inferior bilateral interstitial pneumonia, overlapping a COPD lung. The nasopharyngeal swab test resulted positive, and the patient was admitted with a diagnosis of COVID-19 pneumonia. On the fifth post-admission day, the patient complained of abdominal pain and sub-occlusion. At the examination, the abdomen was tender and mildly sore, most in the inferior quadrants. The abdomen X-ray revealed a centroabdominal air-fluid level, without perforation signs. An abdominal CT with contrast was then executed, which showed acute diverticulitis with free intraperitoneal air, and a collec- tion with a diameter of 8 centimeters on the left side of the abdomen. Pelvic free fluid was also described (Figure 3).

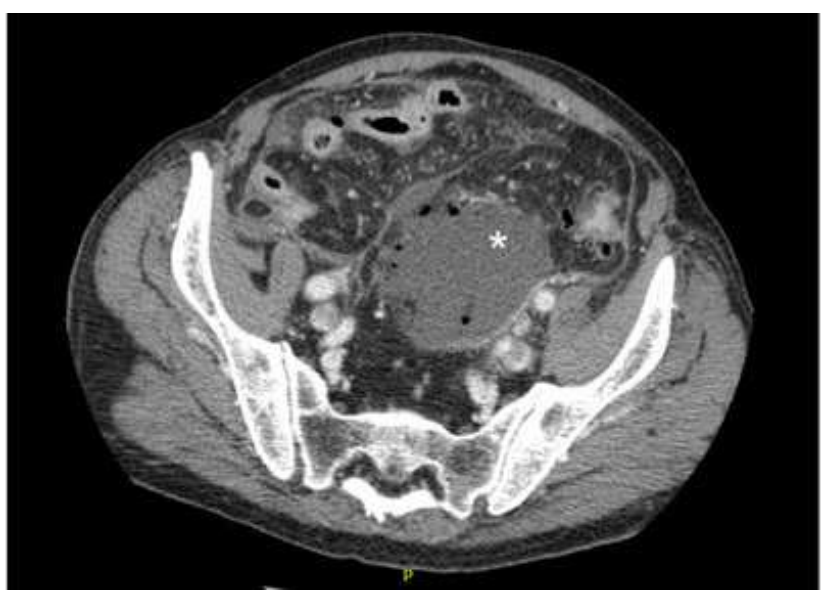

Figure 3. Abdominal CT with contrast (Case 3) showing acute diverticulitis with free intraperitoneal air and the 8-centimeter collection $\left({ }^{*}\right)$.

Then, a chest X-ray documented a mild regression of the interstitial bilateral thickening (Figure 4), while blood tests revealed an increase in the white blood cell count $\left(13^{\prime} 090 \times 10^{\wedge} 9 / \mathrm{L}\right)$, as well as CRP (165.5mg/dL).

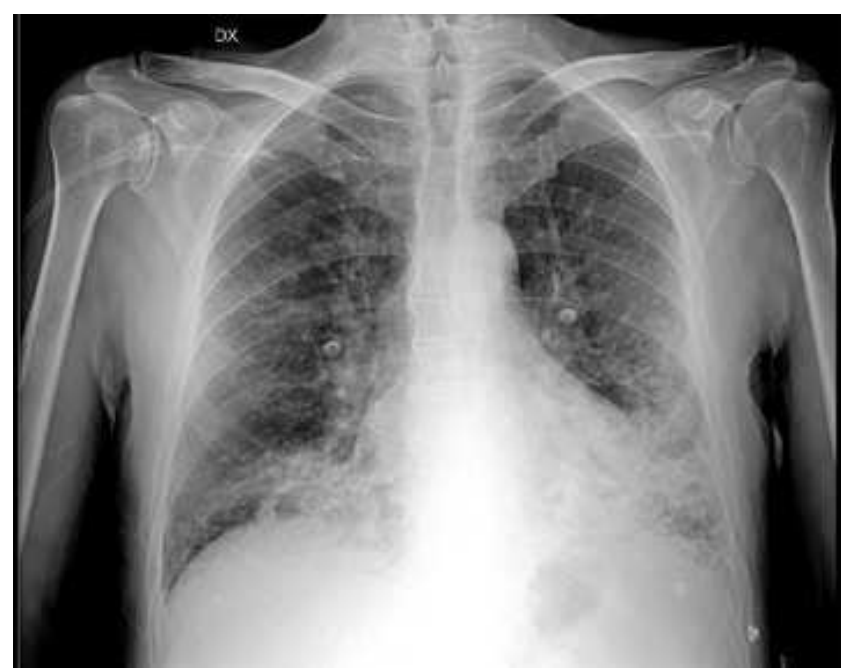

Figure 4. Chest X-ray (Case 3) showing an inferior bilateral interstitial pneumonia, overlapping a COPD lung.

Considering the clinical presentation, the blood test results, and the patient's age and comorbidities, it was decided to avoid a risky open surgical intervention, and, under local anesthesia and US-guide, a percutaneous paramedian puncture of the abdominal collection was performed. 160 millimeters of purulent liquid was drained. Two-way drainage was left, until the tenth post-procedural day. During the hospital 
stay, there was a gradual relief in the patient's symptoms as well as an improvement in the physical objective presentation.

An abdominal CT scan control was scheduled on the ninth postprocedural day with the following finding: complete resolution of the gross peri-sigmoidal collection (Figure 5). After an extended-spectrum antibiotic therapy, the patient was discharged home, asymptomatic of Sars-CoV-2 infection.

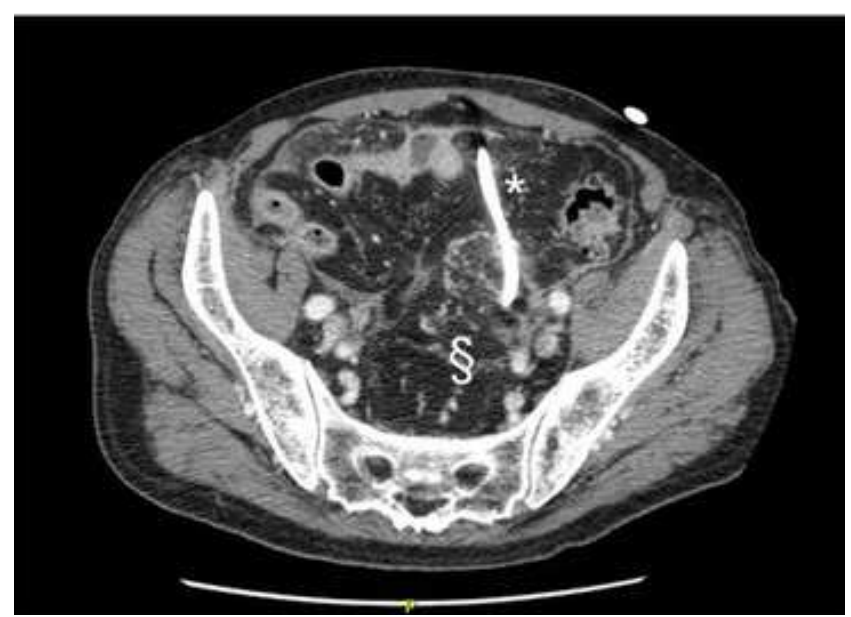

Figure 5. Abdominal CT scan control (Case 3) showing complete resolution of the gross perisigmoidal collection (§). The * indicates the percutaneous drainage.

\section{DISCUSSION}

No perioperative nor postoperative surgical complications occurred in both cases 1 and 2. No peri- and post-procedural complications occurred in case 3.

In CASE 1, the anatomical sample was a sigmoid colon tract with a length of 13 centimeters. Histopathological findings were consistent with diverticular disease and acute perforated diverticulitis. Realtime reverse transcriptase-polymerase chain reaction (rRT-PCR) of peritoneal fluid swab did not detect viral RNA.

In CASE 2, the anatomical sample was an 11-centimeters-long sigma tract, rich in diverticula. The final diagnosis was acute perforated diverticulitis with abscessualization.

A stoma swab test was obtained in both cases, and no viral load was detected during rRT-PCR analysis.

In both cases, the reversal of Hartmann's procedure was carried out five months after Hartmann's procedure, without perioperative complications, and both patients were discharged after a regular clinical course.

In CASE 3, a perianal swab and a drainage fluid swab were collected. In both samples, the rRT-PCR analysis was negative for Sars-CoV-2.

The decision-making process in cases of emergency surgery during a Sars-CoV2 infection is challenging because, on one hand, indications for emergency surgery should be the same as always; on the other hand, the main current concern is to balance the timely treatment of these urgent cases, considering perioperative COVID-19 morbidity and mortality ${ }^{1}$. It is demonstrated that a positive Sars-CoV-2 swab should delay surgery for at least 4 weeks, in order to reduce perioperative mortality 4 , and patients with suspected or confirmed SarsCoV-2 infection need more frequent postoperative follow-up checks ${ }^{1}$. Notwithstanding, as colorectal surgeons, we needed evidence on the management of COVID-19 surgical patients during emergencies. We tried to follow the current general guidelines for the treatment of acute diverticulitis ${ }^{6}$ as much as possible. For the treatment of these cases, general paradigms found in the literature were also used ${ }^{9}$. We subsequently tried to combine the current European guidelines, written just before the pandemic, and indications we could find in the "COVID age" literature, to leave a practical written inheritance for the treatment of such cases in the future. More in detail, we searched for indications on the surgical approach (open vs. laparoscopy), on the surgical technique (primary anastomosis vs. anastomosis and covering ileostomy vs. Hartmann's procedure), and on general practical suggestions for COVID-19 patients affected by acute perforated diverticulitis. We found practical indications on surgeons' education and training, as well as guidance on the benefits and risks of the laparoscopic approach in COVID age surgery ${ }^{10}$. Other recommendations were to minimize the number of personnel and materials and to reduce contaminating particle dispersion, as well as to develop support strategies in the management of the emergency ${ }^{11}$. Presenting this case series, we hope to arouse a debate on expert opinions, recommendations, and practical directions for the treatment of similar conditions in the future. The debate is necessary due to the 
prevalence of diverticulosis in Western countries, which affects half of the population over the age of $60^{12}$. Also, acute diverticulitis is a common cause of surgical emergency, as the most frequent complication of colonic diverticulosis in the elderly population ${ }^{13}$.

The problem should be taken into account by general and colorectal surgeons, even for the following reasons. After the "stay-at-home" orders during the first phase of the pandemic, some authors reported a significant decrease in diverticulitis episodes ${ }^{14}$. On the contrary, patients who delay presentation for acute diverticulitis may develop a more severe or complicated disease. It is also demonstrated that, while nonCOVID-19 emergency visits were diminished, patients who presented to the emergency rooms with acute diverticulitis were more likely to show greater disease severity, associated with an abscess formation at the CT $\operatorname{scan}^{15}$. Therefore, a reduction in the number of cases of diverticulitis could result in a parallel and paradoxical increase in the severity of the hospitalized cases. This fact should warn us when diagnosing and treating such patients.

Here we presented 3 cases of acute diverticulitis management in patients who had a recent diagnosis of SarsCoV-2 infection. As at the beginning of the pandemic there was a total lack of indications for management of such cases, we tried to follow standard evidence as well as pandemicrelated indications: "try a conservative solution for those patients who can require them, avoid invasive treatments, if you can, and avoid excessive exposition of the healthcare personnel to the virus". Adapting to an unprecedent scenario, we decided to keep the surgical procedure as simple as possible, avoiding extended techniques ${ }^{16}$, as posteriorly suggested in a review by Benítez C. et al. Therefore, in case 1 , we decided to perform a Hartmann's procedure because of the septic status of the patient, to avoid the risk of a possible anastomotic leakage, and to reduce the potential risks of prolonged exposure to the virus. Furthermore, a multidisciplinary consult heavily influenced the decision-making process. As suggested by the European guidelines, we tried a conservative treatment in case 2, because of the size of the diverticular abscess. Finally, as clinical conditions were worsening, and the diameter of the abscess became larger, we had to switch to surgical therapy (Hartmann's procedure, for the same reasons as case 1). Case 3 happened in October, when many indications were already available in the literature. A Brazilian work by Parreira J. G. et al. showed indications about non-operative treatment in non-traumatic emergencies. In the pandemic context, if the operation can be postponed without increasing the risk for the patient, it seems to be the best option ${ }^{17}$. Surgical treatment was probably indicated also in our case 3 , but the general conditions of the patient and the adequate control of the abdominal infectious condition made us decide on a less invasive procedure. The procedure was effective, and the outcome was satisfactory and complicationfree. In a period in which a lot of things must be understood about Sars-CoV-2 infection, we also tried to find the virus in body fluids and gastrointestinal samples of our patients, using a traditional swab test and Real-time reverse transcriptasepolymerase chain reaction, as other authors did before. Candellier et al. reported no evidence of viral load in the peritoneal dialysis effluent specimen, even if patients' nasopharyngeal swabs obtained at the admission had shown a high viral load ${ }^{18}$. On the other hand, the first detection of SarsCoV-2 in the peritoneal waste of a patient who had undergone dialysis was documented by Vischini et al. in March $2020^{19}$. The presence of the virus in the peritoneal fluid was confirmed by Barberis et al. in March 2020, when they found a positive swab test made on the abdominal fluid in a patient who underwent a subtotal colectomy plus ileostomy for hemorrhagic shock ${ }^{20}$. In none of our patients, we found a viral load in the abdominal fluid nor drainage. Neither Romero-Velez et al. found SarsCoV-2 on multiple samples of the peritoneum of an asymptomatic patient undergoing laparoscopic appendectomy ${ }^{21}$.

As regards the research of Sars-CoV2 RNA in other specimens, we did not find any viral presence in the stoma swab test nor the anal swab test of our patients. On the other hand, some authors reported the presence of the virus in feces specimens: in a study by Chen, 42 patients tested positive for Sars-CoV-2 respiratory infection, 28 of them had laboratory confirmation of the 
presence of the virus in stool specimens ${ }^{22}$. Another Chinese study found rRT-PCR to be positive on feces samples in 44 of 153 patients ${ }^{23}$. Besides, in a systematic review of 95 articles, it is reported that in 91 of the included studies, Sars-CoV-2 RNA was identified in gastrointestinal specimens from at least one of the included patients. Furthermore, 49 studies reported persistently positive swab tests in gastrointestinal specimens after respiratory swabs have become negative ${ }^{24}$.

These contradictory findings are yet to be confirmed by other studies and reviews involving more numerous samples, but so far it can be said that:

- Fecal-oral transmission is possible and possibly more long-lasting than respiratory transmission;

- Healthcare personnel should pay attention to manipulating gastrointestinal or other COVID-19 patients' fluids;

- Respiratory contamination of the swab tests used on other fluids seems to be possible;

- It would be desirable if swab tests for the research on respiratory specimens could be validated.

\section{CONCLUSION}

The management of surgical emergencies in COVID-19 patients is an outlined practice during this pandemic. An increasing number of publications are contributing to defining how to manage patients with a diagnosis of Sars-CoV-2 infection. The number of work on COVID patients affected by a colorectal acute disease, especially acute perforated diverticulitis, is increasing. In a continuously evolving scenario, we hope to make a contribution to the management of colorectal COVID emergencies, leaving our modest practical written inheritance for the treatment of such cases in the future. Moreover, the present work aims to give a contribution to the management of such surgical emergencies, as well as to warn colorectal surgeons about possible challenges. For instance, during the pandemic, some cases are likely to present in later stages and with serious complications. Concerning the presence of the virus in gastrointestinal samples and peritoneal fluids, further studies involving larger series of patients with validated tests are needed, to better define the operative risks for the personnel and the possible fecal-oral transmission of the virus.

\section{REFERENCES}

1. Gao Y, Xi H, Chen, L. Emergency Surgery in Suspected COVID-19 Patients With Acute Abdomen: Case Series and Perspectives. Ann Surg. 2020;272(1):e38-9. doi: $10.1097 /$ SLA.0000000000003961.

2. COVIDSurg Collaborative. Mortality and pulmonary complications in patients undergoing surgery with perioperative SARS-CoV2 infection: an international cohort study. Lancet. 2020;396(10243):27-38.

doi: 10.1016/S0140-6736(20)31182-X.

3. Di Saverio S, Pata F, Gallo G, Carrano F, Scorza A, Sileri P, et al. Coronavirus pandemic and colorectal surgery: practical advice based on the Italian experience. Colorectal Dis. 2020;22(6):625-34.

doi: 10.1111 /codi.15056.

4. COVIDSurg Collaborative. Delaying surgery for patients with a previous SARS-CoV-2 infection. $\mathrm{Br} \mathrm{J}$ Surg. 2020;107(12):e601-2. doi: $10.1002 /$ bjs. 12050 .

5. Costanzi A, Monteleone M, Confalonieri M, Colletti G, Frattaruolo C, Magni C, et al. Covid-19 and acute perforated diverticulitis: management and surgical timing. Minerva Chir. 2020;75(6):468-70.

doi: 10.23736/S0026-4733.20.08487-4.

6. Sartelli M, Weber DG, Kluger Y, et al. 2020 update of the WSES guidelines for the management of acute colonic diverticulitis in the emergency setting. World J Emerg Surg. 2020;15(1):32. doi:10.1186/s13017-020-00313-4.

7. Agha RA, Fowler AJ, Saeta A, Barai I, Rajmohan S, Orgill DP, et al. The SCARE Statement: Consensusbased surgical case report guidelines. Int $\mathrm{J}$ Surg. 2016;4:180-6. doi: 10.1016/j.ijsu.2016.08.014.

8. Agha RA, Borrelli MR, Farwana R, Koshy K, Fowler AJ, Orgill DP, et al. The PROCESS 2018 statement: Updating Consensus Preferred Reporting Of Case Series in Surgery (PROCESS) guidelines. Int J Surg. 2018;60:27982. doi: 10.1016/j.ijsu.2018.10.031. 
9. Fingerhut A, Veyrie N. Complicated diverticular disease: the changing paradigm for treatment. Rev. Col. Bras. Cir. 2012;39(4):322-7. doi: $10.1590 / \mathrm{s} 0100-69912012000400013$.

10. Ramos RF, Lima DL, Benevenuto DS. Recommendations of the Brazilian College of Surgeons for laparoscopic surgery during the COVID-19 pandemic. Rev. Col. Bras. Cir. 2020;47: e20202570.

doi: 10.1590/0100-6991e-20202570

11. Correia MITD, Ramos RF, Bahten LCV. The surgeons and the COVID-19 pandemic. Os cirurgiões e a pandemia do COVID-19. Rev. Col. Bras. Cir. 2020;47:e20202536.

doi:10.1590/0100-6991e-20202536.

12. Feuerstein JD, Falchuk KR. Diverticulosis and Diverticulitis. Mayo Clin Proc. 2016;91(8):1094-104.

doi: 10.1016/j.mayocp.2016.03.012.

13. Hinchey E., Schaal PG, Richards GK. Treatment of perforated diverticular disease of the colon. Adv Surg. 1978;12:85-109.

14. Soriano C, Kaplan JA, Law JK, Williams BL, Blackmore CC, Simianu VV. The Immediate, Hospital-Level Impact of Stay-at-Home Order on Diverticulitis Burden. J Gastrointest. 2021;25(2):533-5.

doi: $10.1007 / \mathrm{s} 11605-020-04798-x$.

15. Zintsmaster MP, Myers DT. Patients avoided important care during the early weeks of the coronavirus pandemic: diverticulitis patients were more likely to present with an abscess on CT. Emerg Radiol. 2021;28(2):279-82. doi: 10.1007/s10140-020-01854-6.

16. BenÍtez CY, Pedival AN, Talal I, et al. Adapting to an unprecedented scenario: surgery during the COVID-19 outbreak. Rev. Col. Bras. Cir. 2020;47:e20202701.

doi:10.1590/0100-6991e-20202701.

17. Parreira JG, Campos T, Antunes PSL, Perlingeiro JAG, Assef JC. Management of non traumatic surgical emergencies during the COVID19 pandemia. Rev. Col. Bras. Cir. 2020;47:e20202614. doi: 10.1590/0100-6991e-20202614.

18. Candellier A, Scohy A, Gillet N, Muylkens B, Morelle J, Belkhir L, et al. Absence of SARS-CoV-2 in the ef- fluent of peritoneal dialysis patients. Perit Dial Int. 2020;40(5):499-503. doi: $10.1177 / 0896860820953061$.

19. Vischini G, D'Alonzo S, Grandaliano G, D'Ascenzo FM. SARS-CoV-2 in the peritoneal waste in a patient treated with peritoneal dialysis. Kidney Int. 2020;98(1):237-8.

doi: $10.1016 /$ j.kint.2020.05.005

20. Barberis A, Rutigliani M, Belli F, Ciferri E, Mori M, Filauro M. SARS-Cov-2 in peritoneal fluid: an important finding in the Covid-19 pandemic. $\mathrm{Br} \mathrm{J}$ Surg. 2020;107(10):e376.

doi: $10.1002 /$ bjs. 11816 .

21. Romero-Velez G, Pereira X, Zenilman A, Camacho D. SARS-Cov-2 Was Not Found in the Peritoneal Fluid of an Asymptomatic Patient Undergoing Laparoscopic Appendectomy. Surg Laparosc Endosc Percutan Tech. 2020;30(6):e43-5.

doi: $10.1097 /$ SLE.0000000000000837.

22. Chen Y, Chen L, Deng Q, Zhang G, $\mathrm{Wu} \mathrm{K}, \mathrm{Ni} \mathrm{L}$, et al. The presence of SARS-CoV-2 RNA in the feces of COVID-19 patients. J Med Virol. 2020;92(7):833-40. doi: $10.1002 / \mathrm{jmv} .25825$.

23. Wang $\mathrm{W}, \mathrm{Xu} \mathrm{Y}$, Gao $\mathrm{R}$, Lu R, Han $\mathrm{K}$, $\mathrm{Wu}$ G, et al. Detection of SARS-CoV-2 in Different Types of Clinical Specimens. JAMA. 2020;323(18):1843-4. doi: $10.1001 /$ jama.2020.3786.

24. van Doorn AS, Meijer B, Frampton CMA, Barclay ML, de Boer NKH. Systematic review with meta-analysis: SARS-CoV-2 stool testing and the potential for faecal-oral transmission. Aliment Pharmacol Ther. 2020;52(8):1276-88. doi: $10.1111 /$ apt.16036.

Conflict of interest: no

Funding source: none

Received in: January 27, 2021

Accepted for publication: June 30, 2021

\section{Mailing address:}

Claudio Guerci

E-mail: guerci.clau@gmail.com claudio.guerci@unimi.it 